\title{
DETERIMINATION OF MACERATION PER CENT OF CANE AND THE PERCENTAGES OF FIBRE AND SUCROSE IN CANE
}

\author{
By José J. Acos's, Factory Superintendent, Central "Juncos",
}

The well-known difficulties experienced in obtaining a representative sample of the cane ground in a sugar factory'make it inconvenient to determine the percentage of fibre and sucrose in cane by direct analysis of the latter, and accordingly, these items are estimated from the data of juice and bagasse analysis, and the weights of cane, mixed juice, and water of maceration.

Sucrose in cane is equal to the sum of sucrose in mixed juice and sucrose lost in baggase. The sucrose in mixed juice is easily obtained from the weight and analysis of said juice; but the sucrose lost finding the weight of the water of maceration. Factories under these conditions ean use ouly one method for calculating percent fibre and sucrose in cane. This method is clearly explained on page 553 of the last edition of Noel Dee's "Cane Sugar."

The following data are daily obtained in these factories:

$\mathrm{C}=$ Tons of Cane ground

G. M. $=$ Tons of Mixed Juice extracted

$\mathrm{B}^{\mathrm{m}}=$ Brix of Mixed Juice extracted

$\mathrm{B}^{\mathrm{n}}=$ Brix of Normal Juice

$\mathrm{B}^{\mathrm{b}}=$ Brix in bagasse per cent bagasse, obtained by dividing the per cent sucrose in bagasse by the purity of juice from the last roll

$\mathrm{F} \% \mathrm{~B}=$ Fibre per cent bagasse obtained from the per cent moisture in bagasse and Brix in Bagasse per cent Bagasse.

If T. F. represents the tons of fibre in cane we have:

$\mathrm{C}-\mathrm{T} . \mathrm{F} .=$ Tons of normal juice in cane.

$(\mathrm{C}-\mathrm{T} . \mathrm{F}.) \mathrm{B}^{\mathrm{n}}=$ Tons of Brix in eane. Also the Tons of Brix in cane is equal to the sum of Tons of Brix in mixed juice and Tons of Brix in Bagasse.

Then :

$$
\begin{aligned}
& (\mathrm{C}-\text { T. F. }) B^{\mathrm{n}}=\text { G. M. } \times \mathrm{B}^{\mathrm{m}}+\frac{\mathrm{B} \times \mathrm{F}}{\mathrm{T} . \mathrm{F} \cdot \mathrm{B}^{\mathrm{b}} ; \text { or }, \mathrm{C} \times \mathrm{B}^{\mathrm{n}}} \\
& \quad+\text { T. F. } \times \mathrm{B}^{\mathrm{n}}=\text { G. M. } \times \mathrm{B}^{\mathrm{m}}+\frac{\mathrm{T} \cdot \mathrm{F} \cdot \mathrm{B}^{\mathrm{b}}}{\mathrm{F} \% \mathrm{~B}}
\end{aligned}
$$


Transpọsing :

$$
\begin{aligned}
& \frac{\text { T. F. } \times B^{b}}{F \% B}+\text { T. F. } \times B^{n}=\mathrm{C} \times B^{n}-G . M . \times B^{m} \\
& \text { T. F. }=\frac{\left(C \times B^{n}-G \cdot M \cdot \times B^{m}\right) F \% B}{B^{n} \times F \% B+B^{n}}
\end{aligned}
$$

Knowing 'T. F. or the tons of fibre in cane, the weight of bagasse is determined.

$$
\text { Tons of Bagasse }=\frac{\text { T. F. } \times 100}{\mathrm{~F} \% \mathrm{~B}}
$$

We have been using this method for determining percent fibre and sucrose in cane.

Commonly a factor or coefficient is used either to multiply or djvide the percent dilution so as to obtain the percent of maceration. Most of the chemists in Porto Rico divide by 0.85 while others multiply by 1.1669 .

As Noel Deer's method is so logical, and the factor or coefficient method so inaceurate, we believe the former method is more exact.

It is argued that the factor for calculating maceration or dilution is carefully determined using sensitive and exact water meters.

We believe that it is a dangerous procedure to assume that a factor obtained while a certain variety of eane, that may be of either plant or rattoon crop and of a given age, in mills adjusted for the oecasion and revolving at a certain lineal velocity, should be taken as true for all canes and all conditions of the mill. It is still more dangerous to apply such factor to another mill or another factory.

Suppose all these variables do not affect the ratio $\frac{\text { Dilution }}{\text { Maceration }} ; 0 *$ in other words, suppose that cane and mill conditions be the same; then, it would not be right to take this ratio as constant when in fact it varies when the amount of maceration is varied.

The coefficient method in vogue implies that the quantity of I ater retained by the bagasse varies with the quantity of maceration used. We are contrary to this belief, for if cane and mill conditions are constant, the quantity of water retained or absorbed by the bagasse is constant when maceration exceeds a determined minimum. Naceration can be diminished to a point where the mill would not extract the added water, thus allowing it to pass entirely to the bagasse.

Representing maceration by $m$ and the quantity of water re- 
tained by bagasse by $c$, a constant, we have that dilution is $\mathrm{m}-\mathrm{c}$ and $\frac{\text { dilution }=m-c}{m a c e r a t i o n ~} m$ It is obvious that this term, far from being a constant, is a variable and varies directly with $m$ while clanging the quantity of maceration.

We installed this year at Central Juncos a General Electric flow-meter for measuring maceration water, and althongh the meter did not work constantly, we had opportunity to check the results obtained with Noel Deer's formula at such times as the meter was working right.

We must insist in the installation of scales for weighing the maceration water. I say scales, because the meters in spite of being exact when they work right, get stuck frequently and cannot be depended upon for continuous work. I beg to recommend the use of Noel Deer's formula when a scale is not available so as to obtain uniform and comparative results in different factories.

Let us not be satisfied with weighing the canes and the juice only; let us weigh also the water of maceration so as to eliminate from our reports the extraction and analysis of the imaginary normal juice, and be able to abolish the use of factors, rather doubtful, and the use of formulae which increase unaroidable errors. In this way we could come closer to the real sucrose per cent in cane-the most important factor given in a laboratory report on which to base judgment on the work done in a factory. 